\title{
Adverse childhood life events and postpartum psychosis in bipolar disorder
}

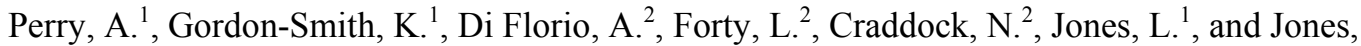 \\ $\mathrm{I}^{2}$ \\ ${ }^{1}$ Department of Psychological Medicine, Institute of Health \& Society, University of \\ Worcester, UK. \\ ${ }^{2}$ Institute of Psychological Medicine \& Clinical Neurosciences, Cardiff University, UK.
}

Corresponding author:

Professor Ian Jones

Institute of Psychological Medicine \& Clinical Neurosciences,

Cardiff University,

Hadyn Ellis Building,

Maindy Road,

Cathays,

Cardiff,

CF24 4HQ

Tel: 02920688477

Email: jonesir1@cf.ac.uk 


\section{Abstract \\ Background}

Women with bipolar disorder are at increased risk of postpartum psychosis. Adverse childhood life events have been associated with depression in the postpartum period, but have been little studied in relation to postpartum psychosis. In this study we investigated whether adverse childhood life events are associated with postpartum psychosis in a large sample of women with bipolar I disorder.

\section{Methods}

Participants were 432 parous women with DSM-IV bipolar I disorder recruited into the Bipolar Disorder Research Network (www.BDRN.org). Diagnoses and lifetime psychopathology, including perinatal episodes, were obtained via a semi-structured interview (Schedules for Clinical Assessment in Neuropsychiatry; Wing et al., 1990) and case-notes. Adverse childhood life events were assessed via self-report and case-notes, and compared between women with postpartum psychosis $(n=208)$ and those without a lifetime history of perinatal mood episodes $(\mathrm{n}=224)$.

\section{Results}

There was no significant difference in the rate of any adverse childhood life event, including childhood sexual abuse, or in the total number of adverse childhood life events between women who experienced postpartum psychosis and those without a lifetime history of perinatal mood episodes, even after controlling for demographic and clinical differences between the groups.

\section{Limitations}

Adverse childhood life events were assessed in adulthood and therefore may be subject to recall errors.

\section{Conclusions}

We found no evidence for an association between adverse childhood life events and the occurrence of postpartum psychosis. Our data suggest that, unlike postpartum depression, childhood adversity does not play a significant role in the triggering of postpartum psychosis in women with bipolar disorder.

Key words: Postpartum psychosis, bipolar disorder, childhood adversity, adverse childhood life events, risk factors 


\section{Introduction}

The postpartum period has been well established as a time of increased vulnerability to relapse in women with bipolar disorder (BD). Almost one in five (17\%) new mothers with $\mathrm{BD}$ are admitted for psychiatric treatment in the early postpartum (Wesseloo et al., 2016), a period in which the risk of admission is significantly greater for these women than at any other time in their lives (Munk-Olsen et al., 2009). Relative to the general population, the risk of postpartum psychosis (PP) is dramatically elevated in women with $\mathrm{BD}$, increasing from one in a thousand to approximately one in five deliveries (Di Florio et al., 2013). The consequences of PP can be devastating for the mother and her wider family. Not only is there an increased risk of maternal suicide (Knight et al., 2015), but risk of harm to the infant, although rare, is also of concern (Spinelli, 2004).

Unfortunately, the factors which increase risk for episodes of PP are still poorly understood. In particular, little is known about the role that adverse childhood life events (ACLEs) may play in the triggering of PP. History of childhood abuse, for example, has previously been associated with depression in the postpartum period (Dennis and Vigod, 2013; Plaza et al., 2012), but has not yet been investigated in relation to PP. Given that ACLEs may increase susceptibility to onset of BD (Fisher and Hosang, 2010) and be associated with a more severe illness course (Erten et al., 2014; Sala et al., 2014; Upthegrove et al., 2015), it is plausible that they could increase risk for episodes of PP in women who have BD.

To date, only one published study has examined ACLEs in relation to PP and found no association (Dowlatshahi and Paykel, 1990). However, only a narrow range of ACLEs was measured (specifically bereavements of immediate family, marital separation of parents and difficulties at school) and the ACLEs were included as part of a general measure of personal history. Furthermore, the sample size in this study was small (33 women in each of the PP and control groups) and the definition of PP was very broad. 
Here we aimed to investigate the relationship between a number of ACLEs, including childhood abuse, and the occurrence of well-defined PP in a large UK sample of parous women with a lifetime DSM-IV (American Psychiatric Association, 2000) diagnosis of bipolar I disorder (BD-I).

\section{Methods}

\section{Participants}

Women were recruited as part of a large, on-going programme of research investigating genetic and non-genetic determinants of mood disorders (Bipolar Disorder Research Network, BDRN; www.bdrn.org). Participants were recruited systematically through UK National Health Service (NHS) Community Mental Health Teams or lithium clinics and nonsystematically via the BDRN website and patient support groups (such as Bipolar UK). The research has UK NHS Research Ethics Committee approval and Research and Development approval in all participating NHS Trusts/Health Boards.

As a principle focus of the BDRN research is to investigate genetic determinants of mood illness, participants are required to be of UK/Eire white ethnicity. Other inclusion criteria specify that participants must: a) be aged 18 years or over; b) have the ability to provide written, informed consent; and, c) have an age of illness onset before 65 years. Participants are excluded if they have only experienced affective illness as a result of substance abuse, medication or, secondary to physical illness.

Rates of postpartum relapse in the BDRN sample have been reported previously (Di Florio et al., 2013). During the period in which data on ACLEs were collected, 1093 parous women with BD-I were recruited to the study, of whom 580 (53\%) experienced lifetime postpartum relapse. 297 (27\% of parous women) experienced PP (defined as an episode of mania, mixed affective state or affective psychosis) within 6 weeks of delivery, consistent with both DSMIV and ICD-10 definitions of the postpartum period. Of the women who experienced PP, 61 
multiparous women also experienced episodes of postpartum non-psychotic depression. 283 (26\%) women experienced episodes of postpartum non-psychotic depression and no PP. We defined the PP group as the 236 women who experienced PP only, to ensure that risk factors for PP were explored independently of those for postpartum non-psychotic depression. The final PP group comprised women with a lifetime history of PP only on whom we also had ACLEs data ( $\mathrm{n}=208,88 \%$ of the PP only group).

The comparison group of women (no perinatal mood episode group, No PME) comprised 268 parous BD-I women with no lifetime history of any affective or psychotic episode during pregnancy or within 6 months following delivery on whom we also had ACLEs data $(n=224$, $84 \%$ of the No PME group). A broader definition of the perinatal period was used to ensure that women did not experience any episodes of mood illness that could be considered related to childbirth.

\section{Psychiatric assessments}

Detailed lifetime psychopathology was assessed using the Schedules for Clinical Assessment in Neuropsychiatry (SCAN, Wing et al., 1990), a semi-structured interview administered by trained research psychiatrists or psychologists. Where available, psychiatric case notes were also screened. Best-estimate lifetime diagnoses according to DSM-IV criteria were made along with ratings of perinatal psychiatric history and lifetime clinical variables. In cases of ambiguity, at least two members of the research team made clinical and diagnostic ratings blind to each other's ratings and consensus was agreed through discussion. Mean kappa statistics were 0.85 for DSM-IV diagnoses and between 0.81 and 0.99 for other key clinical categorical variables. Mean intra-class correlation coefficients were between 0.91 and 0.97 for key clinical continuous variables. 


\section{Measurement of adverse childhood life events}

History of ACLEs was obtained using the BDRN Childhood Life Events Questionnaire (CLEQ, see Upthegrove et al., 2015). The CLEQ was administered verbally to all participants following the SCAN interview once rapport had been established. Participants were asked if they had experienced one or more childhood events before the age of 16 years, which are listed below. Due to the sensitive nature of such events, we chose to not specifically ask about experiences of childhood abuse. Instead, participants were given the opportunity to disclose additional events by being asked "Are there any other significant life events you experienced as a child that are not mentioned above?" Case notes were also reviewed for any mention of ACLEs including abuse.

Participants also completed the self-report Brief Life Events Questionnaire (BLEQ) asking about severe life events based on the list proposed by Brugha et al. (1985). An open question was added to the questionnaire, which asked participants "Do you think that there is anything that has happened to you during your life which has contributed to you becoming unwell?" Answers were further examined for evidence of any ACLEs.

These sources of information were combined to code the presence or absence of the following types of ACLE occurring before the age of 16 years for each participant: (1) Any abuse (sexual and/or physical and/or emotional), (2) sexual abuse, (3) physical abuse, (4) emotional abuse, (5) death of parent, (6) death of sibling, (7) death of a close friend, (8) divorce and/or separation of parents, and (9) serious illness requiring hospitalisation.

\section{Statistical analysis}

Data were analysed using SPSS version 21. Chi-squared tests were used to compare the prevalence of each ACLE between the PP and No PME groups, followed by logistic regression models adjusted for demographic and lifetime clinical variables that differed 
between groups. We also examined whether total number of ACLEs differed between groups using a Mann-Whitney U test.

\section{Results}

Women in the PP group were significantly younger at interview $(\mathrm{p}<0.001)$ and at age of illness onset (defined as age at first impairment due to mood illness, $\mathrm{p}<0.001$ ) than women in the No PME group, but were older at age of first pregnancy $(\mathrm{p}=0.019)$ (Table I). They were more likely to have completed higher education $(\mathrm{p}=0.003)$ and be recruited nonsystematically ( $\mathrm{p}=0.003$ ), and experienced fewer episodes of depression per illness year $(\mathrm{p}=0.039)$ than women in the No PME group (Table I). We therefore controlled for these differences in subsequent analyses.

\section{(INSERT TABLE I)}

We did not find an association between any ACLE and history of PP (Table II), and there remained no significant associations after adjusting for differences in age, education, recruitment method, number of illness episodes, age at onset, and age at first pregnancy. We did not find a significant difference in the total number of ACLEs between groups (median in $\mathrm{PP}$ group=1, IQR=1, range=0-4; No PME group=1, IQR=1, range=0-4; $=0.745$ ).

(INSERT TABLE II)

\section{Discussion}

In a large, well-characterised UK sample we did not find any evidence to suggest a relationship between a range of adverse life events in childhood and the occurrence of PP in women with bipolar I disorder. We are the first to report these findings in women with bipolar disorder. 
Unlike studies which have shown childhood abuse, and specifically childhood sexual abuse, to be associated with depression in the postpartum (Dennis and Vigod, 2013; Plaza et al., 2012), we did not find this in relation to PP. Our findings are consistent with those of previous studies which have reported no association between adverse life events in adulthood or in the 12 months prior to pregnancy and the onset of PP (Brockington et al., 1990;

Dowlatshahi and Paykel, 1990; Marks et al., 1992). Only one previous small study investigated childhood adversity in relation to $\mathrm{PP}$, and also did not find any relationship (Dowlatshahi and Paykel, 1990). Combined, our findings extend those of previous research, indicating that in addition to proximal life stress, more distal life stressors also do not appear to influence risk for PP.

There are, however, a number of factors that have been found in previous studies to be associated with increased risk of PP. Evidence has implicated obstetric complications (Hellerstedt et al., 2013), primiparity (Di Florio et al., 2014) genetic variation (Jones et al., 2007), immunological factors (Bergink et al., 2013) and sustained sleep loss during delivery and the early postpartum (Sharma et al., 2004). The findings of this study are consistent with previous literature that points to biological factors as being of central importance in the aetiology of PP. This is in contrast to postpartum mood disorders more generally where psychological and social factors have been found to play a vital role.

Our findings have implications for clinical practice, suggesting that, in contrast to postpartum depression, experience of childhood adversity should not be a decisive factor when evaluating individual risk for postpartum psychosis among women with bipolar disorder.

\section{Limitations}

Our findings are subject to limitations. First, women in our sample were all of UK/Eire white ethnicity and so our findings may not be generalisable to other populations. Secondly, women were interviewed in adult life and so it is possible that reporting of ACLEs was 
subject to recall errors. Despite this, it is argued that the recall of severe trauma such as childhood sexual abuse does not rely heavily on the judgement or interpretation of participants, thus leading to reduced rates of false positives (Hardt and Rutter, 2004). Thirdly, participants were not asked directly about their experiences of childhood abuse using a specific, validated questionnaire. Instead, they were required to voluntarily disclose any abuse history meaning the prevalence of abuse may have been underreported. Disclosure of abuse has however been shown to be more likely when the word 'abuse' is not used in questions pertaining to childhood experiences (Thombs et al., 2006). Furthermore, psychiatric case notes and self-completed questionnaires were also screened for any mention of childhood abuse that was not disclosed during the face-to-face interview. Fourthly, it is possible that we did not find a significant association between childhood sexual abuse and PP due to lack of statistical power. Reassuringly however, based on published effect sizes in postpartum depression (Plaza et al., 2012) our sample size of 432 women (208 PP; 224 No PME) has $>95 \%$ power to detect a between-group difference in the frequency of childhood sexual abuse. Finally, as this is the first study to investigate the relationship between ACLEs and PP in women with BD-I our findings require independent replication.

\section{Conclusion and implications for future research}

Our findings indicate that, in contrast to postpartum depression, ACLEs are not associated with vulnerability to $\mathrm{PP}$ in women with $\mathrm{BD}$. These findings are consistent with biological factors playing a more important role in the aetiology of severe postpartum episodes and suggest that the presence or absence of ACLEs should not play a major role in individualising the risk assessment for episodes of postpartum psychosis in women with bipolar disorder considering pregnancy. 


\section{Acknowledgements}

The authors would like to thank the funding sources and all members of the Bipolar Disorder Research Network (www.bdrn.org). We also wish to express our gratitude to all the individuals who kindly gave their time to participate in this research. 
American Psychiatric Association, 2000. DSM-IV, Diagnostic and Statistical Manual of Mental Disorders 4th edition TR.

Bergink, V., Burgerhout, K.M., Weigelt, K., Pop, V.J., de Wit, H., Drexhage, R.C., Kushner, S.A., Drexhage, H.A., 2013. Immune system dysregulation in firstonset postpartum psychosis. Biol. Psychiatry 73, 1000-1007.

Brockington, I.F., Martin, C., Brown, G.W., Goldberg, D., Margison, F., 1990. Stress and puerperal psychosis. Br. J. Psychiatry 157, 331-334.

Brugha, T., Bebbington, P., Tennant, C., Hurry, J., 1985. The list of threatening experiences: a subset of 12 life event categories with considerable long-term contextual threat. Psychol. Med. 15, 189-194.

Dennis, C.-L., Vigod, S., 2013. The relationship between postpartum depression, domestic violence, childhood violence, and substance use: epidemiologic study of a large community sample. Violence Against Women 19, 503-17.

Di Florio, A., Forty, L., Gordon-Smith, K., Heron, J., Jones, L., Craddock, N., Jones, I., 2013. Perinatal episodes across the mood disorder spectrum. JAMA Psychiatry 70, 168-75.

Di Florio, A., Jones, L., Forty, L., Gordon-Smith, K., Robertson Blackmore, E., Heron, J., Craddock, N., Jones, I., 2014. Mood disorders and parity - A clue to the aetiology of the postpartum trigger. J. Affect. Disord. 152-154, 334-339.

Dowlatshahi, D., Paykel, E.S., 1990. Life events and social stress in puerperal psychoses: absence of effect. Psychol. Med. 20, 655-662.

Erten, E., Funda Uney, A., Saatçioğlu, Ö., Özdemir, A., F1stıkçı, N., Çakmak, D., 2014. Effects of childhood trauma and clinical features on determining quality of life in patients with bipolar I disorder. J. Affect. Disord. 162, 107-13.

Fisher, H., Hosang, G., 2010. Childhood maltreatment and bipolar disorder : A critical review of the evidence. Mind Brain 1, 1-11.

Hardt, J., Rutter, M., 2004. Validity of adult retrospective reports of adverse childhood experiences: Review of the evidence. J. Child Psychol. Psychiatry Allied Discip. 45, 260-273.

Hellerstedt, W.L., Phelan, S.M., Cnattingius, S., Hultman, C.M., Harlow, B.L., 2013. Are prenatal, obstetric, and infant complications associated with postpartum psychosis among women with pre-conception psychiatric hospitalisations? BJOG An Int. J. Obstet. Gynaecol. 120, 446-455.

Jones, I., Hamshere, M., Nangle, J.M., Bennett, P., Green, E., Heron, J., Segurado, R., Lambert, D., Holmans, P., Corvin, A., Owen, M., Jones, L., Gill, M., Craddock, N., 2007. Bipolar affective puerperal psychosis: Genome-wide significant evidence for linkage to chromosome 16. Am. J. Psychiatry 164, 1099-1104.

Knight, M., Tuffnell, D., Kenyon, S., Shakespeare, J., Gray, R., Kurinczuk, J. (Eds) on behalf of MBRRACE-UK., 2015. Saving lives, improving mothers' care Surveillance of maternal deaths in the UK 2011-2013 and lessons learned to inform maternity care from the UK and Ireland Confidential Enquiries into Maternal Deaths and Morbidity 2009-2013. Oxford.

Marks, M.N., Wieck, A., Checkley, S.A., Kumar, R., 1992. Contribution of psychological and social factors to psychotic and non-psychotic relapse after childbirth in women with previous histories of affective disorder. J. Affect. Disord. 24, 253-263.

Munk-Olsen, T., Laursen, T.M., Mendelson, T., Pedersen, C.B., Mors, O., Mortensen, P.B., 2009. Risks and predictors of readmission for a mental disorder during the postpartum period. Arch. Gen. Psychiatry 66, 189-195.

Plaza, A., Garcia-Esteve, L., Torres, A., Ascaso, C., Gelabert, E., Luisa Imaz, M., 
Navarro, P., Valdés, M., Martín-Santos, R., 2012. Childhood physical abuse as a common risk factor for depression and thyroid dysfunction in the earlier postpartum. Psychiatry Res. 200, 329-35.

Sala, R., Goldstein, B.I., Wang, S., Blanco, C., 2014. Childhood maltreatment and the course of bipolar disorders among adults: epidemiologic evidence of doseresponse effects. J. Affect. Disord. 165, 74-80.

Sharma, V., Smith, A., Khan, M., 2004. The relationship between duration of labour, time of delivery, and puerperal psychosis. J. Affect. Disord. 83, 215-220.

Spinelli, M.G., 2004. Maternal Infanticide Associated With Mental Illness: Prevention and the Promise of Saved Lives. Am. J. Psychiatry 161, 1548-1557. Thombs, B.D., Bernstein, D.P., Ziegelstein, R.C., Scher, C.D., Forde, D.R., Walker, E. a, Stein, M.B., 2006. An evaluation of screening questions for childhood abuse in 2 community samples: implications for clinical practice. Arch. Intern. Med. 166, 2020-2026.

Upthegrove, R., Chard, C., Jones, L., Gordon-Smith, K., Forty, L., Jones, I., Craddock, N., 2015. Adverse childhood events and psychosis in bipolar affective disorder. Br. J. Psychiatry 206, 191-197.

Wesseloo, R., Kamperman, A.M., Munk-Olsen, T., Pop, V.J.M., Kushner, S.A., Bergink, V., 2016. Risk of postpartum relapse in bipolar disorder and postpartum psychosis: A systematic review and meta-analysis. Am. J. Psychiatry 173, 117 127.

Wing, J.K., Babor, T., Brugha, T., Burke, J., Cooper, J.E., Giel, R., Jablenski, A., Regier, D., Sartorius, N., 1990. SCAN: Schedules for clinical assessment in neuropsychiatry. Arch. Gen. Psychiatry. 
Table I. Demographics, lifetime clinical characteristics and perinatal history of 432 women with BD-I according to perinatal psychiatric history.

\begin{tabular}{|c|c|c|c|}
\hline & $\begin{array}{c}\text { No PME } \\
(\mathrm{n}=224)\end{array}$ & $\underset{(\mathrm{n}=208)}{\mathbf{P P}}$ & p- value ${ }^{\mathrm{b}}$ \\
\hline \multicolumn{4}{|l|}{ Age at interview (years) } \\
\hline Median (IQR) & $52(16)$ & $47(16)$ & $<0.001$ \\
\hline Range & $24-73$ & $21-79$ & \\
\hline \multicolumn{4}{|l|}{ Education } \\
\hline No higher education & $89(40.8 \%)$ & $52(26.9 \%)$ & 0.003 \\
\hline Higher education & $129(59.2 \%)$ & $141(73.1 \%)$ & \\
\hline \multicolumn{4}{|l|}{ Method of Recruitment } \\
\hline Non-systematic & $139(62.6 \%)$ & $157(75.8 \%)$ & 0.003 \\
\hline Systematic & $83(37.4 \%)$ & $50(24.2 \%)$ & \\
\hline \multicolumn{4}{|c|}{ Number of episodes of mania per illness year (avg.) } \\
\hline Median (IQR) & $0.23(0.34)$ & $0.25(0.32)$ & 0.452 \\
\hline Range & $0.02-10.87$ & $0.04-3.16$ & \\
\hline \multicolumn{4}{|c|}{$\begin{array}{l}\text { Number of episodes of depression per illness year } \\
\text { (avg.) }\end{array}$} \\
\hline Median (IQR) & $0.28(0.43)$ & $0.21(0.42)$ & 0.039 \\
\hline Range & $0-10.87$ & $0-6.10$ & \\
\hline \multicolumn{4}{|l|}{ Age at illness onset (years) } \\
\hline Median (IQR) & $27(17)$ & $23(10)$ & $<0.001$ \\
\hline Range & $10-45$ & $10-39$ & \\
\hline \multicolumn{4}{|l|}{ Age at $1^{\text {st }}$ pregnancy (years) } \\
\hline Median (IQR) & $24.5(7)$ & $27(5)$ & 0.019 \\
\hline Range & $13-38$ & $19-38$ & \\
\hline \multicolumn{4}{|l|}{ Number of deliveries } \\
\hline Median (IQR) & $2(1)$ & $2(1)$ & 0.561 \\
\hline Range & $1-6$ & $1-9$ & \\
\hline
\end{tabular}

Ns differ due to missing data.

aBD-I: Bipolar I disorder, No PME: No lifetime history of any perinatal mood episode, PP: Lifetime history of postpartum psychosis

bearson's Chi-Square or Mann Whitney-U test. 
Table II. Number and prevalence of adverse childhood life events in 432 women with BD-I ${ }^{\mathrm{a}}$ according to perinatal psychiatric history.

\begin{tabular}{|c|c|c|c|}
\hline & $\begin{array}{c}\text { No PME } \\
(\mathrm{n}=224)\end{array}$ & $\underset{(\mathrm{n}=208)}{\mathbf{P P}}$ & p-value \\
\hline \multicolumn{4}{|l|}{ Number of ACLEs } \\
\hline Median (IQR) & $1(1)$ & $1(1)$ & 0.876 \\
\hline Range & $0-4$ & $0-4$ & \\
\hline \multicolumn{4}{|l|}{ Death of a parent } \\
\hline Absent & $202(90.2 \%)$ & $191(92.3 \%)$ & 0.444 \\
\hline Present & $22(9.8 \%)$ & $16(7.7 \%)$ & \\
\hline \multicolumn{4}{|l|}{ Death of a sibling } \\
\hline Absent & $214(95.5)$ & $196(94.7 \%)$ & 0.682 \\
\hline Present & $10(4.5 \%)$ & $11(5.3 \%)$ & \\
\hline \multicolumn{4}{|l|}{ Death of a close friend } \\
\hline Absent & $203(90.6 \%)$ & $187(90.3 \%)$ & 0.919 \\
\hline Present & $21(9.4 \%)$ & $20(9.7 \%)$ & \\
\hline \multicolumn{4}{|c|}{ Divorce/separation of parents } \\
\hline Absent & $190(85.6 \%)$ & $170(82.1 \%)$ & 0.330 \\
\hline Present & $32(14.4 \%)$ & $37(17.9 \%)$ & \\
\hline \multicolumn{4}{|l|}{ Serious Illness } \\
\hline Absent & $177(79.0 \%)$ & $170(82.1 \%)$ & 0.416 \\
\hline Present & $47(21.0 \%)$ & $37(17.9 \%)$ & \\
\hline \multicolumn{4}{|l|}{${\text { Any } \text { abuse }^{c}}^{c}$} \\
\hline Absent & $185(86.4 \%)$ & $157(80.5 \%)$ & 0.105 \\
\hline Present & $29(13.6 \%)$ & $38(19.5 \%)$ & \\
\hline \multicolumn{4}{|l|}{ Emotional abuse } \\
\hline Absent & $216(96.4 \%)$ & $201(96.6 \%)$ & 0.907 \\
\hline Present & $8(3.6 \%)$ & $7(3.4 \%)$ & \\
\hline \multicolumn{4}{|l|}{ Physical abuse } \\
\hline Absent & $202(94.4 \%)$ & $180(92.3 \%)$ & 0.396 \\
\hline Present & $12(5.6 \%)$ & $15(7.7 \%)$ & \\
\hline \multicolumn{4}{|l|}{ Sexual abuse } \\
\hline Absent & $197(92.1 \%)$ & $169(86.7 \%)$ & 0.076 \\
\hline Present & $17(7.9 \%)$ & $26(13.3 \%)$ & \\
\hline
\end{tabular}

Ns vary due to missing data

aBD-I: Bipolar I disorder, No PME: No lifetime history of perinatal mood episodes, PP: Lifetime history of postpartum psychosis. 'Pearson's Chi Square test

${ }^{\circ}$ Emotional, physical or sexual abuse 